\title{
Enhancement Health Care Workers Engagement in the Light of Advanced Technology: Employees' Perspectives
}

\author{
SHREEN GABER ${ }^{1}$ \\ Corresponding author: ${ }^{1} \mathrm{PhD}$, in Nursing, Nursing Administration Department- Faculty of Nursing- Cairo University, Cairo - Egypt, +20 \\ 1008144971, Shreen17@cu.edu.eg
}

\begin{abstract}
Regardless of the size of the hospital, the leaders have critical responsibilities to engage the employee in some situations. So you are in luck if you have the most precious tool of technologies usage as an enhancement variable.

Aim: This study aimed to explore Employee Engagement factors in the light of advanced technology.

Design: An exploratory correlation study design was exploited in this study.

Sample\& Setting: a cross-sectional sample of 350 different category employees was employed.

Tools: an adapted engagement questionnaire was used to collect the pertinent facts.

Results: The main discoveries of this study exhibited that, in the light of technology, many factors are important for enhancing work engagement; these factors are leadership, teamwork, social engagement, staffing\& resource capability.....etc.

Respectively: These factors did not differ between the studied group work engagements concerning neither their working department nor relation to their gender, but there was a highly significant difference between the studied group work engagements to their years of experience

Conclusion: technology using can enhance employee engagement. Although many factors enhance employee engagement, the advanced technologies make those factors differ in their priority and importance.

Recommendations: all organizations should promote technologies induction within limits that help in employees' engagement.

Also, to achieve a higher level of work engagement when deploying technology, it's important to distinguish between tacit and explicit knowledge.
\end{abstract}

Keywords (MeSH words): technology, engagement, employees, organization.

\section{INTRODUCTION}

Improving workers' engagement is fundamental to a company's culture, specifically when the technology is induced in all settings as well as its long-term profitability. There are a lot of ways to enhance employee engagement from recognition, reward their efforts, communications, ect. Certainly, in our digital age, technology may make this type of interaction even easier and more enjoyable. However, in this research, the study will illustrate different factors stated from the employee perspectives that improve their engagement considering the advanced technology that is used in their units. ${ }^{12}$

Regardless of the size or scale of the hospital, the change agent has a critical responsibility in the clinical Setting accordingly, to engage the employee in the provided care, responsibilities, decisions, etc. Adding to that, young, newly hired workers are ambitious for various facilities, benefits, and means of engagement. So, if you are ready to engage your employees and boost productivity and morale, you are in luck. ${ }^{8}, 9$

You already have the most valuable technical tool at your disposal. Consider how these tools, which range from investing in collaboration tools to boosting meetings with amusing gadgets, can help your organization increase participation. ${ }^{2}, 3$

Every day, we are surrounded by various advanced technology, especially at the office. It can be used for more than just producing reports and designing things. With the correct tools, technology can keep employees engaged every day. ${ }^{7}, 12,18$

Recently all researchers have commonly stressed employee engagement and applying technology to all clinical areas that help. Early attempts at integration laudably focused on workers and how they could harness new digital tools for a newly hired work simplification. For example, many worldwide organizations placed technology as a construction engagement tool, emphasizing that health care workers should be dealing, integrated, and learning with. Other institutions have noted that technology integration must focus not on the technology itself, but on the facilitation and orientation of the technology enables for the all health team, specifically newly hired, that will help to maximize workers engagement which definitely promotes organization productivity. ${ }^{13}$

Leaders and educators became the focus of attention with the departure of the Technological and conveyed its role in enhancing their engagement in all related decisions and output. There is a vital link between employee performance, interactions, communication, behaviors with the technology investment in their work wherever these technological computer systems are used in the labs, nursing station, diagnostic units, radiology, human resources, etc. Although the researches lacked how the empirical data which illustrate how the induced technology affect workers performance almost of the recent researches confirmed that, the highly productive, engaged employee was likely to used unit systems which facilitate their engagement. ${ }^{2}, 15$

Health educators see the digitalization of onsite job instruction as both a challenging and inspiring component of their employment. Prior research has primarily focused on negative employee experiences, such as techno pressures. As a result, the current study aims to see how 
technology-related workplace resources, such as selfefficacy and autonomy, influence employee positive clinical well-being and techno-work engagement. ${ }^{13}$

Significance of the study: The significance of engaging human resources is an unquestionable issue nowadays. According to (Carrillo, 2017) more than 45 percent of the workforce in the institutions are disengaged worldwide, which is a threatened number that increased significantly in the organization which adopts the advanced technology in their performance output. Today, one of the essential elements in all employee satisfaction and retention tactics in the institutions is to understand the true importance of employee engagement. Definitely, predominantly when the technology induces in their daily routine work, so in this study, the researcher will explore to what extent health team engagement can be improved in the light of technology induction in all clinical areas. All engagement factors are stated from the employee perspectives considering the advanced technology used in their units.

\section{SUBJECTS\& METHODS}

Aim of the study: This study intended to explore engagement enhancing factors in the light of advanced technology.

Research questions: To satisfy the aim of this research, these research questions were expressed:

- What are the factors that enhance employee engagement in the light of advanced technology?

Is there a relationship between work engagement and technology used?

Study Design: An exploratory correlation study design was exploited in this study. Exploratory research is flexible and delivers the original foundation for future research. A correlation study is a form of research design in which a researcher attempts to determine the types of correlations that exist between variables. In naturally occurring simple terms, correlation research seeks to figure out if two or more variables are related. 1,6

Sample\& Setting: A cross-sectional sample of different categories of health care workers includes $(n=350$ employee) who work in three different private hospitals affiliated to Cairo and Giza governorates. The wide percentage held of them were office worker, nursing staff, technicians, ,,,,,,, etc.

- Including criteria

1. Workers who deal directly with technology in their work

2. Workers who have spent at least 2 years in their job title.

3. Workers who are willing to participate in this study.

Tools: To achieve the aim of this study the following tool was used to collect the pertinent data. Employee engagement questionnaire: developed to assess the perception of the employees regarding the work engagement factors. This questionnaire was adapted from (Schaufeli, 2012). is composed of two parts

First part: personal data characteristics which include: gender, age, marital status, level of education, years of experience, job department, use of technology,,,,,,,, etc.

Second part: work engagement factors questionnaire composed of 50 questions segmented into ten sub-items as following: collaboration, teamwork, leadership, staffing \& resource capability, reciprocal health team members' communications, Technology-Based Workgroups,
Training\& Education, Social Engagement, Recognition\& acknowledgment, Gamification.

Scoring system: each item has three responses ranging from agreeing (score of 2) which mean that the nurses agree that this item is considered as the main factor in enhancing engagement in the presence of workplace technology, to some extent (score 1) which mean that the nurses agree to some extent that, this item considered as the main factor in enhancing engagement in the presence of workplace technology, disagree(score of 0 )which mean that the nurses disagree that this item considered as a factor in enhancing engagement in the presence of workplace technology.

Tool validity: Content validity is defined as the degree to which instrument measures what it is supposed to measure, identification of the content must accurately be represented by the test items. A group of experts is consulted to identify tool content and validity. By five experts consisted of three professors in the Nursing Administration department and two assistant professors in the Faculty of Engineering. Each expert was given the task of reviewing the data gathering tool for content coverage, clarity, wording structure, and overall appearance. Based on experts' comments and recommendations minor changes had been made to the tool.

Pilot study: Pilot researches are pretesting procedures that involve all procedures and materials involved in data collection before the actual data collection begins and have a specific goal that to estimate the response rates for identifying optimal design characteristics that guarantee the success and effectiveness of the study. ${ }^{4}$

A pilot research involving 35 different health care personnel was conducted. which are constituted $10 \%$ of organizations workers working at the time of data collection to test the applicability and the clarity of the questionnaires and to estimate the time needed to complete them. The Result showed that the time spent in filling the questionnaire was estimated between 4-7 minutes. Based on the pilot study analysis there was no alteration been done in the tool. A pilot study was built in the total study sample.

Ethical consideration: Official permission to conduct the proposed study and approval letters was taken from the three hospital director. Oral consensuses were obtained from each department manager. The researcher informed the participants that participation in the study was voluntary with no hazards and told them about the possibility to depart at any time, followed by the enlightenment of the purpose and nature of the study. Participants were assured about the confidentiality of the information and observed coding of data.

Data collection: After construction, validity, and pilot study of the data collection instrument, a reliability test was performed by Cronbach's alpha test, and the Result was (79\%) which means that the Result of the current study is almost reliable. The items included in the questionnaire are internally consistent. The highest total score of the tool was 100, divided into different levels as follows: from 0 to 32 considered as low level. From 33 to 66 is considered as moderate level. From 67 to 100 is considered a high level. The current study was performed through a defined process initiated with official permission. Approvals were 
granted to carry out the present study; the researcher started to collect the pertinent data. The researcher interviewed the participants who admit contributing to the survey after the elucidation of the study nature, aim, and implication to assess the feasibility, objectivity, and applicability of the study tools. Besides, to estimate the time needed to fill the data collection sheets.

The employee engagement self-administration questionnaire was filled individually. The researcher gave the questionnaire by hand to the employee who accepted participation, explained it to them and how to fill it. The researcher waited with the participants when they filled the questionnaire to answer any questions or clarification if need. Then, the researcher took the filled questionnaire at the same time after it has been filled. The participants took from 4-7 minutes to fill the self-administered sheet; after that, the Reliability test was performed by Cronbach's alpha test, and the Result was (79\%). And there was no modification so that the 35 worker who shared in the pilot study were drawn in the actual total study sample. After one week, the researcher started to collect the rest of the sheets for three hours twice weekly. This process of data collection began from the beginning of January 2020 to the end of February 2020. The collected data were tabulated and analyzed by SPSS.

Data analysis: Upon accomplishing data collection, the data were recorded, tabulated, and analyzed by computer using the "statistical package for social science" (SPSS. version 21). Descriptive statistics and frequency distribution of data were accomplished. Also, the needed inferential statistics analysis was performed using ANOVA, person correlation, and t-test. A significant value was considered $p$ $<0.05$.

Table1 Frequency distribution of socio-demographic data of the studied sample $(\mathrm{N}=350)$

\begin{tabular}{|c|c|c|}
\hline Item & No & $\%$ \\
\hline \multicolumn{3}{|l|}{ Gender } \\
\hline Male & 68 & 19.4 \\
\hline Female & 282 & 80.6 \\
\hline \multicolumn{3}{|l|}{ Age } \\
\hline $20<30$ & 212 & 59.6 \\
\hline $30<40$ & 101 & 28.9 \\
\hline $40<50$ & 35 & 10.0 \\
\hline $50 \geq 60$ & 2 & .6 \\
\hline Total & 350 & 100 \\
\hline \multicolumn{3}{|l|}{ Experience } \\
\hline Less than 5 years & 114 & 31.6 \\
\hline $5<10$ & 133 & 37.2 \\
\hline $10<15$ & 54 & 15.4 \\
\hline $15-<20$ & 26 & 7.4 \\
\hline $20<30$ & 21 & 6.0 \\
\hline $30 \geq 40$ & 2 & .6 \\
\hline Total & 350 & 100 \\
\hline \multicolumn{3}{|l|}{ Current job } \\
\hline staff nurse & 270 & 77.1 \\
\hline Technician & 25 & 7.1 \\
\hline Office worker & 38 & 10.6 \\
\hline Dietitian & 10 & 2.8 \\
\hline Administrator & 7 & 2.0 \\
\hline Total & 350 & 100 \\
\hline \multicolumn{3}{|l|}{ Qualification } \\
\hline Secondary schools & 100 & 28.5 \\
\hline Technical institute & 129 & 36.1 \\
\hline bachelor & 104 & 29.1 \\
\hline postgraduates & 17 & 4.8 \\
\hline Total & 350 & 100 \\
\hline
\end{tabular}

Table 2 Frequency distribution regarding work engagement factors in the light of advanced technology $(n=350)$

\begin{tabular}{|l|l|l|l|l|l|l|}
\hline \multirow{2}{*}{} & \multicolumn{2}{|c|}{ Disagree } & \multicolumn{2}{l|}{$\begin{array}{l}\text { To some } \\
\text { extent }\end{array}$} & \multicolumn{2}{l|}{$\begin{array}{l}\text { Strongly } \\
\text { agree }\end{array}$} \\
\cline { 2 - 8 } & No & $\%$ & No & $\%$ & No & $\%$ \\
\hline Collaboration & 18 & 5.1 & 148 & 42.3 & 184 & 52.6 \\
\hline Teamwork & 16 & 4.6 & 74 & 21.1 & 260 & 74.3 \\
\hline Leadership & 0 & 0 & 39 & 11.1 & 311 & 88.9 \\
\hline $\begin{array}{l}\text { Staffing\& } \\
\text { Resource } \\
\text { capability }\end{array}$ & 0 & 0 & 116 & 33.1 & 234 & 66.9 \\
\hline $\begin{array}{l}\text { Reciprocal Health } \\
\text { Team Members' } \\
\text { communications }\end{array}$ & 9 & 2.6 & 151 & 43.1 & 190 & 54.3 \\
\hline $\begin{array}{l}\text { Technology } \\
\text { Based } \\
\text { Workgroups }\end{array}$ & 7 & 2 & 115 & 32.9 & 228 & 65.1 \\
\hline $\begin{array}{l}\text { Training\& } \\
\text { Education, }\end{array}$ & 29 & 8.3 & 106 & 30.3 & 215 & 61.4 \\
\hline $\begin{array}{l}\text { Social } \\
\text { Engagement }\end{array}$ & 14 & 4 & 76 & 21.7 & 260 & 74.3 \\
\hline $\begin{array}{l}\text { Recognition\& } \\
\text { acknowledgment }\end{array}$ & 38 & 10.9 & 103 & 29.4 & 209 & 59.7 \\
\hline Gamification & 72 & 20.6 & 62 & 17.7 & 216 & 61.7 \\
\hline
\end{tabular}

Table 3 Correlation between the studied sample engagement and their usage of technology $(n=350)$

\begin{tabular}{|l|l|l|}
\hline Variables & $r$ & $p$ \\
\hline $\begin{array}{l}\text { Technologies usage and total } \\
\text { scores of work engagement }\end{array}$ & 0.032 & 0.044 \\
\hline
\end{tabular}

Table 4 the difference among the studied sample in relation to their department and years of experience and their engagement $(n=350)$

\begin{tabular}{|c|c|c|c|c|c|}
\hline 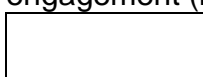 & $\begin{array}{l}\text { Sum of } \\
\text { Squares }\end{array}$ & $\mathrm{df}$ & $\begin{array}{l}\text { Mean } \\
\text { Square }\end{array}$ & $\mathrm{F}$ & $p$ \\
\hline $\begin{array}{l}\text { Between } \\
\text { Groups } \\
\text { Within Groups } \\
\text { Total } \\
\text { (department ) }\end{array}$ & $\begin{array}{l}24.977 \\
77832.783 \\
77857.760\end{array}$ & $\begin{array}{l}4 \\
345 \\
349\end{array}$ & $\begin{array}{l}6.244 \\
225.602\end{array}$ & .028 & .999 \\
\hline
\end{tabular}

Table 5 the difference among the studied sample in relation to their gender and their engagement $(n=350)$

\begin{tabular}{|c|c|c|c|c|c|}
\hline \multirow[t]{2}{*}{ 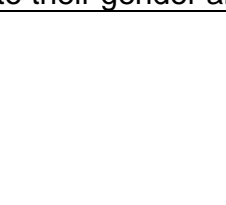 } & \multicolumn{2}{|c|}{$\begin{array}{l}\text { Levene's Test } \\
\text { for Equality of } \\
\text { Variances }\end{array}$} & \multicolumn{3}{|c|}{ t-test for Equality of Means } \\
\hline & $\mathrm{F}$ & Sig. & $\mathrm{t}$ & $\mathrm{df}$ & $\begin{array}{l}\text { Sig. } \\
(2- \\
\text { tailed }) \\
\end{array}$ \\
\hline $\begin{array}{l}\text { Equal variances } \\
\text { assumed } \\
\text { Equal variances } \\
\text { not assumed }\end{array}$ & .404 & .526 & $\begin{array}{l}1.072 \\
1.094\end{array}$ & $\begin{array}{l}348 \\
104.350\end{array}$ & $\begin{array}{l}.285 \\
.277\end{array}$ \\
\hline
\end{tabular}

Table 6 the difference among the studied sample concerning their years of experience and their engagement $(n=350)$

\begin{tabular}{|l|l|l|l|l|l|}
\hline & $\begin{array}{l}\text { Sum of } \\
\text { Squares }\end{array}$ & $\mathrm{df}$ & $\begin{array}{l}\text { Mean } \\
\text { Square }\end{array}$ & $\mathrm{F}$ & $\mathrm{p}$ \\
\hline Between & & & & & \\
Groups & 2760.835 & 5 & 552.167 & 2.529 & .029 \\
$\begin{array}{l}\text { Within } \\
\text { Groups }\end{array}$ & 75096.925 & 344 & 218.305 & & \\
Total & 77857.760 & 349 & & & \\
\hline
\end{tabular}




\section{RESULTS}

More than $80 \%$ of the studied sample were female $(80.6 \%)$, the majority of their age ranged between $20-30$, approximately one third have experience from $5-10$ years $(37.2 \%)$, about two-thirds of them work as a staff nurse, the highest percentage of them were technical while only 2 have postgraduates certificates $(36.1, .6 \%)$ respectively.( table1)

The majority of the study sample stated that all the ten listed factors are important for work engagement, but they stated that the four top factors that enhance engagement in the light of technology are: leadership, teamwork, social engagement, staffing\& resource capability (88,9\%, 74,3\%, 74,3,66,9) respectively.( table 2 )

There is a highly significant correlation between technology using and employee engagement. .( table 3)

There was no statistically significant difference between the studied group work engagements in relation to their working department. (Table 4)

There was no difference between the studied group work engagements in relation to their gender. (Table 5). There was a highly significance difference between the studied group work engagements in relation to their years of experience (Table 6).

\section{DISCUSSION}

The purpose of this study was to explore engagementenhancing factors in the light of technology-inducing work. The study sounds out that the top factor that enhances engagement in the light of technology are: leadership, teamwork, social engagement, staffing \& resource capability besides other factors such as collaboration, reciprocal health team members' communications, Technology-Based Workgroups, Training\& Education, Recognition\& acknowledgment, Gamification

Results showed that there was no significant statistical difference between the studied group work engagements in relation to their working department and their gender. While the was a highly statistically significant difference between the studied group work engagements in relation to their years of experience

From the researcher's point of view, this Result may be related to the significant role of the leaders to influence their subordinates. Also, teamwork is considered as the main factor that pushes the organizational climate positively. This is evidenced that, the importance of teamwork and leadership don't change even after induction of the advanced technology. Besides, if the leader was competent and the resources were not available, it's aimless effort, so, the availability of manpower/ supplies resources is so crucial for effective work engagement. Also, the difference in the studied group years of experience may be due to the highest experience employees the more equipped with the needed capabilities that help them to engage in their work safely regardless of their department of work or their gender.

The results matched 5 study's purpose of learning more about how information technology affects nurses' ongoing job procedures and engagement. Data was collected from 74 nurses in four wards of Dutch organizations. The main discovery was that nurses' knowledge appeared to be a substantial forecaster of their work engagement. Nurses' explicit knowledge, on the other hand, has a minor impact on work engagement. Surprisingly, information technology only has a major impact on nurses' explicit knowledge, not their knowledge or work engagement. It's critical to distinguish between nurses' implicit and explicit knowledge when implementing technology.

Also, in some particular, the current study not matched with the An evaluation of the effects of actions to improve information technology systems was done. in improved management performance, and improved organizational outcomes by Searching in different databases Randomized and non-randomized trials, and time-series studies comparing and the main findings showed that information systems have a positive impact on service quality (health worker motivation, health worker training, and health information index scores) when they are part of a comprehensive service quality improvement initiative. Finally, the author states, "There is a lack in treatments exploring information support outside clinical management, such as human resources, finances, and governance".To inform rigorous intervention design and assessment approaches, we need a clearer understanding of the causal pathways by which information assistance may effect change in managerial decision making. ${ }^{9}$

Furthermore, the findings were consistent with a study conducted by 16 that looked into the link between job engagement and leadership traits. It also looked into the role of inclusive leadership as a facilitating factor in the relationship between work engagement and the use of innovative technology. 374 Chinese managers were questioned in April 2018. The main result stated that inclusive leadership was significantly and positively correlated to innovative behaviour and work engagement in the presence of innovative technology. The researcher suggests that measures be taken to improve the level of inclusive leadership among leaders and to strengthen the pioneering behaviour of managers

8 conducted a study to evaluate the infusion of technology into services and analyze technology as an enabler to control service gaps and internal inconsistencies among personnel.The key findings show that service organizations are increasingly relying on technology to overcome internal and external service gaps. Various technologies are assisting in the interconnection of stakeholders by facilitating the creation of streamlined service procedures.

Newer technologies have the potential to connect people more efficiently, boosting service quality by closing internal service gaps.. The author recommended studying the technology implication in relation to the service gaps model extensively and external customer service.

According to previous research, ${ }^{10,11}$ Stated that, Higher techno-work engagement is associated to three technology-related job resources, and higher techno-work engagement is linked to technology-related self-efficacy.. As part of a broader study effort, data was collected from $(\mathrm{N}=183)$. The major findings revealed that self-efficacy in technology had the greatest impact on work engagement. Furthermore, autonomy and assistance connected to technology were statistically significant determinants of techno-work engagement. Similar workplace resources, 
which influence general job engagement, appear to be significant in the context of techno-work engagement, according to the findings. From the age of the schools,

\section{CONCLUSION}

According to the findings of a recent study, in the light of technology, there were many factors that are important for enhancing work engagement, these factors are leadership, teamwork, social engagement, staffing\& resource capability.....etc respectively. These factors did not differ between the studied group work engagements in relation to neither their working department nor relation to their gender, but there was a highly significant difference between the studied group work engagements in relation to their years of experience. There for The following recommendations were made: Researchers are encouraged to use a larger sample of hospitals and including teaching and private sectors, all organizations should promote technologies induction within limits that help in employees' engagement, Also to achieve a higher work engagement employees have to be systematically distinguished when applying technologies.

\section{REFERENCES}

1. Bourgault, Patricia, et al. Mixed-method research design in nursing sciences, or when a research question calls for qualitative and quantitative strategies. Recherche en soins infirmiers, 2010, 4: 20-28.

2. Carrillo, Hilda; CASTELLANO, Joseph F.; KEUNE, Timothy M. Employee engagement in public accounting firms: Getting millennial staff excited about the work environment. The CPA Journal, 2017, 87.12: 36-41.

3. Gaber, Shreen. Impact of Emergency Clinical Work Environment on Nurses' Satisfaction and Intension to Leave. Egyptian Journal of Health Care, 2020, 11.2: 319-330.

4. Gupta, G. S., Bailey, D., Demidenko, S., \& Carnegie, D. (Eds.). Recent Advances in Robotics and Automation 2019, Vol. 480. Springer.

5. HENDRIKS, Paul HJ; LIGTHART, Paul EM; SCHOUTETEN, Roel LJ. Knowledge management, health information technology and nurses' work engagement. Health care management review, 2016, 41.3: 256-266.

6. Hulley, Malakar, N. K., Hulley, G. C., Hook, S. J., Laraby, K., Cook, M., \& Schott, J. R. An operational land surface temperature product for Landsat thermal data: Methodology and validation. IEEE Transactions on Geoscience and Remote Sensing, 2018, 56(10), 5717-5735.
7. International Society for Technology in Education. ISTE Standards for Educators. 2017, Retrieved from www.iste.org/standards/for-educators.

8. Kazi, R., \& Prabhu, S. Management of service gaps by infusion of technology. Telecom Business Review,2015 8(1), 10.

9. Leon, N., Balakrishna, Y., Hohlfeld, A., Odendaal, W. A., Schmidt, B. M., Zweigenthal, V.,\& Daniels, K. Routine Health Information System (RHIS) improvements for strengthened health system management. Cochrane Database of Systematic Reviews,2020 (8)

10. Mäkiniemi, J.-P. I., Ahola, S., \& Joensuu, J. How are technology-related workplace resources associated with techno-work engagement among a group of Finnish teachers?. Seminar.net,2019 15(1), 1-21. Retrievedfrom https://journals.hioa.no/index.php/seminar/article/view/2919.

11. Michaud, F., Boissy, P., Labonté, D., Briere, S., Perreault, K., Corriveau, H., ... \&Létourneau, DExploratory design and evaluation of a homecare teleassistive mobile robotic system. Mechatronics, 2010; 20(7), 751-766.

12. Mishra, A., \& Warr, A. A systems view of technology infusion. Championing technology infusion in teacher preparation: A framework for supporting future educators.2020

13. Reiser, R. A., \& Dempsey, J. V. (Eds.). Trends and issues in instructional design and technology. Boston, MA: Pearson 2018.

14. Schaufeli, W. B. The measurement of work engagement. In Research Methods in Occupational Health Psychology2012; 162-178. Routledge.

15. Schaufeli, W. B., Bakker, A. B., \&Salanova, MThe measurement of work engagement with a short questionnaire: A cross-national study. Educational and psychological measurement, 2006; 66(4), 701-716.

16. Wang, Y. X., Yang, Y. J., Wang, Y., Su, D., Li, S. W., Zhang, T., \& Li, H. P. The mediating role of inclusive leadership: Work engagement and innovative behaviour among Chinese head nurses. Journal of nursing management, 2019; 27(4), 688-696.

17. Zakaria, Yehia A., Taema, Mohamed K., Ismael, Saied M. and Elhabashy, S. Impact of a Suggested Nursing Protocol on the Occurrence of Medical Device-Related Pressure Ulcers in Critically III Patients" Central European Journal of Nursing and Midwifery,2018; 9(4), 924-931. DOI: 10.15452/CEJNM.2018.09.0025.

18. Elhabashy S, Abdelgawad EM. The history of nursing profession in ancient Egyptian society. International Journal of Africa Nursing Sciences. 2019 Jan 1;11:100174. 